\title{
Lanthanum Chloride Inhibits LPS Mediated Expressions of Pro-Inflammatory Cytokines and Adhesion Molecules in HUVECs: Involvement of NF-kB-Jmjd3 Signaling
}

\author{
Xia Chen Min Xiu Juanjuan Xing Shaoqing Yu Dinghong Min Fei Guo \\ Burns Institute, the First Affiliated Hospital of Nanchang University, Nanchang, China
}

\section{Key Words}

Lanthanum chloride $•$ Nuclear factor $\mathrm{KB} \cdot \mathrm{Jmjd} 3 \cdot \mathrm{H} 3 \mathrm{~K} 27 \mathrm{Me} 3 \cdot$ Vascular inflammation

\begin{abstract}
Background/Aims: To investigate the regulation of $\mathrm{LaCl}_{3}$ on lipopolysaccharides (LPS)induced pro-inflammatory cytokines and adhesion molecules in human umbilical vein endothelial cells (HUVECs). Methods: Primary cultured HUVECs were pretreated with $2.5 \mu \mathrm{M}$ $\mathrm{LaCl}_{3}$ for $30 \mathrm{~min}$ followed by $1 \mu \mathrm{g} / \mathrm{ml}$ LPS for $2 \mathrm{~h}$. Pro-inflammatory cytokine and adhesion molecule expressions were determined by real-time RT-PCR and ELISA. NF-kB/p65 nuclear translocation was examined by immunofluorescence and immuno-blot, and its DNA-binding activity was measured by chemiluminescence. Recruitment of NF-KB/p65, Jmjd3, and $\mathrm{H} 3 \mathrm{~K} 27$ me3 to gene promoter regions was determined by ChIP-qPCR. Results: $\mathrm{LaCl}_{3}$ exhibited no cytotoxic effects to primary HUVECs at concentrations $\leq 50 \mu \mathrm{M}$. LPS-mediated TNF- $\alpha$, IL$1 \beta$, IL-6, MMP-9, and ICAM-1 production, nuclear translocation, and DNA-binding activity of $\mathrm{NF}-\mathrm{kB} / \mathrm{p} 65$, as well as Jmjd3 expression, were all reduced significantly by $\mathrm{LaCl}_{3}$. Furthermore, $\mathrm{LaCl}_{3}$ treatment significantly impaired LPS-induced enrichment of NF-KB/p65 to the promoter regions of TNF- $\alpha, M M P-9, I L-1 \beta, I C A M-1$, and $I L-6$; and of Jmjd 3 to the promoter regions of TNF- $\alpha, M M P-9, I L-1 \beta$, and IL-6. H3K27me3 abundance in the promoter regions of TNF- $\alpha$ and ICAM-1 increased significantly in following $\mathrm{LaCl}_{3}$ treatment. Conclusion: $\mathrm{LaCl}_{3}$ inhibits proinflammatory cytokine and adhesion molecule expressions induced by LPS in HUVECs. NF-KB and histone demethylase Jmjd3 are involved in this effect.

\section{Introduction}

Vascular inflammation plays important roles in various diseases including cardiovascular diseases and diabetes [1-3]. It is well-established that pro-inflammatory cytokines and adhesion molecules contribute to these diseases. For example, tumor necrosis factor (TNF)- $\alpha$ and interleukin (IL)- 6 are up-regulated in inflammatory states associated with obesity and diabetic metabolic disturbances, participating in damage to organs and 
arteries, and maintaining the inflammatory state [4]. Inflammatory cytokines like TNF- $\alpha$ also activate genes like matrix metalloproteinases (MMPS), which are responsible for collagen matrix remodeling [5], and intercellular adhesion molecule (ICAM)-1, which is responsible for recruiting immune cells [6]. Cyclooxygenase (COX)-2 is up-regulated by inflammation and accounts for the large amount of prostaglandins observed in inflamed tissues [7]. Vascular endothelial cells participate in inflammation both as mediator-releasing and target cells. Since vascular endothelial cells line the interior of the blood vessels, they are constantly exposed to all compounds found in the blood and play a key role in many pathological processes [8]. Their dysfunction is a critical underlying cause of vascular inflammationrelated diseases [9-12].

The main epigenetic processes in the regulation of gene expression are now wellknown. Indeed, the accessibility of chromatin is regulated by epigenetic mechanisms [13]. These epigenetic processes regulate transcription through various post-translational histone modifications, commonly referred to as the "histone code". Over the past few years, evidence has been found of the involvement of epigenetic mechanisms to pathological changes of human vascular cells $[14,15]$. Tri-methylation of lysine 27 in histone H3 (H3K27me3) has been revealed to be associated with transcriptional repression [16]. Histone lysine demethylases are chromatin modifiers that play important roles in many pathological processes such as inflammation and cancer, making them potentially attractive drug targets. One of the well-studied histone lysine demethylases is the jumonji domain containing 3 (Jmjd3, also known as Kdm6b), which removes methyl groups from H3K27me3/2 [17]. Jmjd3 was found to be directly up-regulated by NF-KB in LPS-induced macrophages [18], highlighting a link between epigenetic regulation and inflammation.

An epidemiological investigation from people living in areas rich in rare earth elements strongly suggested that blood rare earth element levels have an impact on blood pressure, blood glucose, and other physiological indexes [19]. In fact, rare earth elements have many applications in medicine such as cerium compounds being applied in burns treatment [20, 21]. Lanthanum, a light rare earth element, has potential applications in medicine [22] and lanthanum carbonate is used in the treatment of hyperphosphatemia [23, 24]. Rare earth elements are reported to possess a number of physiological effects such as immune regulation [25, 26], anti-virus [27], and anticancer [28-30].

Previous studies by our group showed that lanthanum inhibits inflammatory gene expression by blocking the NF- $\kappa$ B pathway of macrophages in LPS-mediated inflammatory conditions $[26,31]$. NF- $\mathrm{kB}$ plays a major role in governing the vascular inflammatory process by directly upregulating pro-inflammatory cytokines and adhesion molecules [32]. However, the epigenetic regulating effects of rare earth elements on human vascular cells remain largely unknown.

Therefore, the aim of the present study was to explore the epigenetic regulation by $\mathrm{LaCl}_{3}$ of the NF- $\kappa \mathrm{B}$ downstream pro-inflammatory cytokines and adhesion molecules in LPSactivated human umbilical vein endothelial cells (HUVECs).

\section{Material and Methods}

Primary culture of human umbilical vein endothelial cells (HUVECs)

The present study was conducted in accordance with the Declaration of Helsinki and was approved by the Ethics Committee of the First Affiliated Hospital of Nanchang University, China (No.: 20150305gf). Umbilical cord donations for research purposes were obtained after written consents from the patients.

HUVECs were isolated from human umbilical cords using collagenase [33] and cultured in endothelial cell medium (ECM; LPS < 0.03 U/ml; Sciencell Research Laboratories, Carlsbad, CA, USA) with endothelial cell growth supplement (ECGS, Cat. \#1052; Sciencell Research Laboratories, Carlsbad, CA, USA), antibiotics (1\% penicillin/streptomycin), and $5 \%$ fetal bovine serum (FBS; LPS < $0.03 \mathrm{U} / \mathrm{ml}$; GIBCO, Invitrogen Inc., Carlsbad, CA, USA). The cells were maintained at $37^{\circ} \mathrm{C}$ in humidified air containing $5 \% \mathrm{CO}_{2}$. Subcultures were performed using trypsin-EDTA. Cells were used at passages 3-5 for the following experiments. Endothelial 


\section{Cellular Physiology Cell Physiol Biochem 2017;42:1713-1724 \\ \begin{tabular}{l|l} 
DOI: 10.1159/000479439 & $\begin{array}{l}\text { O 2017 The Author(s). Published by S. Karger AG, Basel } \\
\text { www.karger.com/cpb }\end{array}$
\end{tabular}}

Chen et al.: $\mathrm{LaCl}_{3}$ Inhibited Inflammation in LPS-Induced HUVECS

cells were identified by typical phase contrast 'cobblestone' morphology and by immunofluorescence to factor VIII antigen.

\section{Treatments}

According to our previous studies [26,31], HUVECs were incubated with LPS $(1 \mu \mathrm{g} / \mathrm{ml}$, from Escherichia coli; serotype 055:B5; Sigma, St Louis, MO, USA) to promote the activation of NF- $\mathrm{\kappa B}$. We found in the preexperiments that the activation of NF-KB in HUVECs peaks at $2 \mathrm{~h}$. Therefore, HUVECs were incubated with 1 $\mu \mathrm{g} / \mathrm{ml}$ LPS for $2 \mathrm{~h}$ to detect NF- $\mathrm{kB} / \mathrm{p} 65$ DNA-binding activity.

To determine the cytotoxicity of lanthanum on HUVECs, the cells were treated with $0,2.5,5,25,50$, 100 , and $200 \mu \mathrm{M}$ of $\mathrm{LaCl}_{3}\left(\mathrm{LaCl}_{3} \cdot 7 \mathrm{H}_{2} \mathrm{O}\right.$, purity: 99.9\%; Sigma, St Louis, MO, USA) for $24 \mathrm{~h}$. To estimate the effects of lanthanum on NF- $\mathrm{kB} / \mathrm{p} 65$, Jmjd3, and H3K27 methylation status in LPS-induced HUVECs, the cells were divided into four groups: LPS group (incubated with $1 \mu \mathrm{g} / \mathrm{ml}$ of LPS), $\mathrm{LaCl}_{3}$ group (incubated with 2.5 $\mu \mathrm{M}$ of $\mathrm{LaCl}_{3}$ ), $\mathrm{LaCl}_{3}+\mathrm{LPS}$ group (pretreated with $2.5 \mu \mathrm{M}$ of $\mathrm{LaCl}_{3}$ for $0.5 \mathrm{~h}$, washed with PBS to remove $\mathrm{LaCl}_{3}$, and then treated with $1 \mu \mathrm{g} / \mathrm{ml}$ of LPS), and control group (cultured with ECM only).

Cell viability

Cell viability assay was estimated using the 3-(4, 5-dimethylthiazol-2-yl) -2, 5-diphenyltetrazolium bromide (MTT) assay [34].

\section{Immunofluorescence}

HUVECs seeded in 24-well cell culture cluster with glass slide were fixed with freshly prepared 3.7\% paraformaldehyde in phosphate-buffered saline (PBS) for $15 \mathrm{~min}$ and permeablized with $0.5 \%$ Triton X-100 at room temperature. Non-specific binding was reduced by blocking the cells with freshly prepared $1 \%$ bovine serum albumin (BSA) in PBS for $1 \mathrm{~h}$ at room temperature. Then, the cells were incubated with goat anti-factor VIII antibody (1:1000; Abcam, Cambridge, MA, USA) or anti-NF- $\mathrm{KB} / \mathrm{p} 65$ antibody (1:100; Santa Cruz Biotechnology, Santa Cruz, CA, USA), washed, and incubated with FITC (fluorescein isothiocyanate)conjugated secondary antibody (Sigma, St Louis, MO, USA). Nuclear staining was completed by DAPI (4', 6-diamidino-2-phenylindole; Sigma, St Louis, MO, USA) staining. The localization and expression of factor VIII and NF-kB/p65 were visualized using a fluorescence microscope (IX71; Olympus, Tokyo, Japan).

Preparation of total protein extracts and of cytosolic and nuclear fractions

RIPA buffer containing protease and phosphatase inhibitors (Beyotime Institute of Biotechnology, Haimen, China) was used to obtain total protein extracts. The nuclear and cytoplasmic fractions were obtained using the NE-PER ${ }^{\circledR}$ Nuclear and Cytoplasmic Extraction Reagents (Thermo Fisher Scientific, Waltham, MA, USA), according to the manufacturer's instructions. The protein concentration was determined by a protein assay reagent (Bio-Rad, Hercules, CA, USA). All extracts were stored in aliquots at $-80^{\circ} \mathrm{C}$ until use.

\section{Western blot}

The HUVECs were processed for western blotting [31]. Total, nuclear, and cytoplasmic extracts (30 $\mu \mathrm{g}$ of protein per lane) were separated by SDS-PAGE (sodium dodecyl sulfate polyacrylamide gel electrophoresis) and transferred onto polyvinylidene fluoride (PVDF) membranes. The bands were detected with rabbit anti-Jmjd3 (Santa Cruz Biotechnology, Santa Cruz, CA, USA), rabbit anti-IкB $\alpha$ (Santa Cruz Biotechnology, Santa Cruz, CA, USA), mouse anti-NF-kB/p65 (Santa Cruz Biotechnology, Santa Cruz, CA, USA), rabbit anti-H3K27me3 antibody (Abcam, Cambridge, MA, USA), and rabbit anti-H3K27me2 antibody (Abcam, Cambridge, MA, USA). Rabbit anti-GAPDH primary antibody (Santa Cruz Biotechnology, Santa Cruz, CA, USA) and Rabbit anti-Lamin B1 (Boster, WuHan, China) were used as reference for total protein and nuclear protein, respectively. The chemiluminescence substrate solution (Pierce, Dallas, TX, USA) was incubated for 5 min.

\section{Nuclear NF- $\kappa B / p 65$ DNA-binding activity}

According to the manufacturer's instructions of the Universal EZ-TFA Transcription Factor Assay Chemiluminescent kit (Millipore corp., Billerica, MA, USA), nuclear extracts from HUVECs were added to the plates containing biotinylated oligonucleotides with NF- $\kappa B$ binding sites (5'-GGGACTTTCC-3'). An NF$\mathrm{\kappa B} / \mathrm{p} 65$ specific competitor oligonucleotide having the same sequence as the NF- $\mathrm{\kappa B}$ capture probe without 
being biotinylated was used as negative control. After $1 \mathrm{~h}$ of incubation at room temperature, the plates were washed and incubated with rabbit anti-NF- $\mathrm{BB} / \mathrm{p} 65$ antibody for $1 \mathrm{~h}$. After washing the plates, antirabbit horseradish peroxidase-conjugated antibody (1:500) was added and washed after $30 \mathrm{~min}$. The chemiluminescence substrate solution was added and incubated for 5-8 min. The reaction was stopped and samples were read at 1-s integration time in a microplate reader (GloMax-96; Promega, Madison, WI, USA).

Quantitative polymerase chain reaction (RT-qPCR)

Total RNA was extracted using TRIZOL (Invitrogen, Carlsbad, CA, USA) from treated HUVECs and quantified by spectrophotometry. RT-qPCR was carried out using a first strand cDNA synthesis kit (Promega, Madison, WI, USA) and SYBR GreenER ${ }^{\mathrm{TM}}$ qPCR SuperMix for ABI PRISM ${ }^{\circledR}$ systems (Invitrogen Inc., Carlsbad, CA, USA). All reactions involved initial denaturation at $95^{\circ} \mathrm{C}$ for $2 \mathrm{~min}$ followed by 40 cycles of $95^{\circ} \mathrm{C}$ for 25 $\mathrm{s}$ and $55^{\circ} \mathrm{C}$ for $45 \mathrm{~s}$. The relative amount of each gene was normalized to the housekeeping gene GAPDH. Relative quantity values were analyzed using the $2^{-\Delta \Delta \mathrm{Ct}}$ method, which reflects the difference in threshold for each target gene relative to that of control group. The primer sequences are listed in Table 1.

\section{Enzyme-linked immunosorbent assay}

ELISA was performed according to the manufacturer's protocol (RayBiotech, Inc., Norcross, GA, USA) for the following pro-inflammatory cytokines and adhesion molecules in the cell culture supernatants: TNF- $\alpha$, IL-1 $\beta$, IL-6, MMP-9, and ICAM-1. Optical density was measured at $450 \mathrm{~nm}$ using a FLUOstar OPTIMA microplate reader (BMG LABTECH GmbH, Ortenberg, Germany).

Chromatin immunoprecipitation and quantitative PCR assay

To quantify the abundance of NF- $\kappa \mathrm{B} / \mathrm{p} 65$, Jmjd3, and H3K27me3 in the promoter regions of the target genes, chromatin immunoprecipitation was performed using a ChIP assay kit (Millipore corp., Billerica, MA, USA). HUVECs were crosslinked with $1 \%$ formaldehyde, washed, and re-suspended in SDS lysis buffer. Nuclei were fragmented by sonication. Chromatin fractions were cleared with protein A-agarose beads followed by immunoprecipitation overnight with anti-H3K27me3 antibody (Abcam, Cambridge, MA, USA), anti-Jmjd3 antibody (Abcam, Cambridge, MA, USA), anti-NF- $\kappa \mathrm{B} / \mathrm{p} 65$ antibody (Abcam, Cambridge, MA, USA), or with control IgG accordingly (Rabbit IgG-ChIP Grade (Abcam, ab171870) for Jmjd3, H3K4me3 and NF-KB; Mouse IgG1 (ab 81032) for H3K27me3). Crosslinking was reversed, followed by proteinase $\mathrm{K}$ digestion. Amplifications of the immunoprecipitated DNA were performed by real-time PCR. All reactions were performed in triplicate in a final volume of $25 \mu \mathrm{l}$. The primer sequences are shown in Table 2. Data was presented as the amount of DNA recovered by specific antibodies relative to DNA enriched by the appropriate IgG controls.

\section{Statistical analysis}

All experiments were independently performed three times with values presented as mean \pm standard error of the mean (SEM). Data
Table 1. Primers used in real-time PCR analysis. F: Forward; R: Reverse

\begin{tabular}{lll}
\hline Gene & Primer & Sequence $\left(5^{\prime} \rightarrow 3\right)$ \\
\hline TNF- $\alpha$ & $\mathrm{F}$ & CCC GAG TGA CAA GAA TGT AG \\
& $\mathrm{R}$ & TGA GGT ACA GGC CCT CTG AT \\
$I L-1 \beta$ & $\mathrm{F}$ & CAG ATG AAG TGC TCC TTC CA \\
& $\mathrm{R}$ & ACC AGC ATC TTC CTC AGC TT \\
$I L-6$ & $\mathrm{~F}$ & AAT GAG GAG ACT TGC CTG GT \\
& $\mathrm{R}$ & GCA GGA ACT GGA TCA GGA CT \\
COX-2 & $\mathrm{F}$ & GCT GGA ACA TGG AAT TAC CC \\
& $\mathrm{R}$ & TGA TTC ATA GGG CTT CAG CA \\
ICAM-1 & $\mathrm{F}$ & TGA TTC ATA GGG CTT CAG CA \\
& $\mathrm{R}$ & TCT GGC TTC GTC AGA ATC AC \\
MMP-9 & F & TCC AGT ACC GAG AGA AAG CC \\
& $\mathrm{R}$ & GCA GGA TGT CAT AGG TCA CG \\
GAPDH & F & CAG GGC TGC TTT TAA CTC TGG T \\
& $\mathrm{R}$ & GAT TTT GGA GGG ATC TCG CT \\
\hline
\end{tabular}

Table 2. Primers used in the ChIP-qPCR analysis

\begin{tabular}{lll}
\hline Gene & Primer & Sequence $(5 ' \rightarrow 3)$ \\
\hline$T N F-\alpha$ & $\mathrm{F}$ & ACC GAG ACA GAA GGT GCA \\
& $\mathrm{R}$ & TGT GCC AAC AAC TGC CTT \\
$I L-1 \beta$ & $\mathrm{F}$ & CTT CCA CTT TGT CCC ACA T \\
& $\mathrm{R}$ & GTG CAG TTG ATG TCC ACA T \\
$I L-6$ & $\mathrm{~F}$ & GGC AAA GAG AAT CTA CAC T \\
& $\mathrm{R}$ & TCT GTT CTG TGC CCT CAT T \\
$I C A M-1$ & $\mathrm{~F}$ & AGG ATT TTC CCA GGC CTT \\
& $\mathrm{R}$ & CCA TCC AGA GAC GCA TAT \\
$M M P-9$ & $\mathrm{~F}$ & CCC ACA AGC TCT GCA GTT \\
& $\mathrm{R}$ & ACC TCC TCC TCT CTC CAC T \\
GAPDH & $\mathrm{F}$ & TAC TAG CGG TTT TAC GGG CG \\
& $\mathrm{R}$ & TCG AAC AGG AGG AGC AGA GAG CGA \\
\hline
\end{tabular}


was analyzed with Prism 6 (GraphPad software Inc., San Diego, CA, USA). Significant differences were evaluated using independent samples $t$ tests except that multiple treatment groups were compared by analysis of variance (ANOVA) with the Tukey's post hoc test. Two-sided $P$-values $<0.05$ were considered significant.

\section{Results}

$\mathrm{LaCl}_{3}$ did not exhibit cytotoxic effect on HUVECs

We successfully isolated HUVECs from human umbilical cords and the cells were identified by the typical "cobblestone" morphology (Fig. 1A) and by immunofluorescence to factor VIII antigen (Fig. 1B). To observe the effect of $\mathrm{LaCl}_{3}$ on the viability of HUVECs, the cells were incubated with $0,2.5,5,25,50,100$, and $200 \mu \mathrm{M}$ of $\mathrm{LaCl}_{3}$ for $24 \mathrm{~h}$. The MTT assay suggested that $\mathrm{LaCl}_{3}$ exhibited no cytotoxic effect at concentrations of $0,2.5,5,25$, and 50 $\mu \mathrm{M}$ (Fig. 1C).

\section{$\mathrm{LaCl}_{3}$ inhibited LPS-induced nuclear translocation and DNA-binding activity of $N F-\kappa B / p 65$} in HUVECs

Knowing that NF- $\kappa \mathrm{B} / \mathrm{p} 65$ signaling is essential in the processes of LPS-mediated inflammatory response [35], translocation of NF- $\mathrm{kB} / \mathrm{p} 65$ from the cytosol to the nuclei was observed in the LPS group, but not in the $\mathrm{LaCl}_{3}+\mathrm{LPS}$ and $\mathrm{LaCl}_{3}$ groups (Fig. 2A), in agreement with the western blot assay of p65 in the nuclear fractions (Fig. 2B). As the NF- $\mathrm{kB} / \mathrm{p} 65$

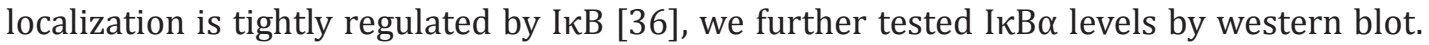

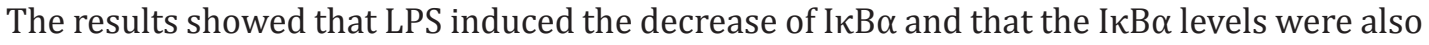
decreased in the $\mathrm{LaCl}_{3}+\mathrm{LPS}$ group, suggesting that the effects of $\mathrm{LaCl}_{3}$ on the translocation of NF- $\kappa \mathrm{B} / \mathrm{p} 65$ was not through inhibiting the degradation of I $\kappa \mathrm{B} \alpha$ in HUVECs induced by LPS (Fig. 2B).

We next sought to determine the DNA-binding activity of p65 from the nuclei extracts. NF- $\kappa B / p 65$ DNA-binding activity was found to increase significantly in the LPS group but not in the other groups, indicating that the LPS-induced DNA-binding activity of p65 can be inhibited by $\mathrm{LaCl}_{3}$ (Fig. 2C).

Fig. 1. Identification of human umbilical vein endothelial cells (HUVECs) and the effect of lanthanum $\left(\mathrm{LaCl}_{3}\right)$ on cell viability of HUVECs. (A) HUVECs were observed under inverted phase contrast microscope (bar = $50 \mu \mathrm{m}$ ). (B) Immunofluorescence to factor VIII antigen further validated HUVECs (bar $=50 \mu \mathrm{m}$ ). Green: FITC; Blue: DAPI. (C) To observe the effect of $\mathrm{LaCl}_{3}$ on the viability of HUVECs, cells were incubated with $0,2.5,5,25$, 50, 100, and $200 \mu \mathrm{M} \mathrm{\textrm {LaCl } _ { 3 }}$ for $24 \mathrm{~h}$ respectively. Data


are shown as mean \pm standard error of the mean (SEM) from three independent experiments in triplicate. $* P<0.05$ vs. $0 \mu \mathrm{M} \mathrm{LaCl}_{3}$. 
Fig. 2. $\mathrm{LaCl}_{3}$ decreased lipopolysaccharides (LPS)-induced NF- $\kappa \mathrm{B} / \mathrm{p} 65$ expression, its nuclear translocation, and its DNA-binding activity in HUVECs. HUVECs were pretreated with $2.5 \mu \mathrm{M}$ of $\mathrm{LaCl}_{3}$ followed by treatment in fresh medium with $1 \mu \mathrm{g} / \mathrm{ml}$ of LPS for $2 \mathrm{~h}$. (A) p65 nuclear translocation was determined by immunofluorescence (bar $=50 \mu \mathrm{m})$. Green: FITC labeled anti-NF$\kappa B / p 65$; Blue: DAPI. (B) Protein expressions of NF- $\kappa \mathrm{B} / \mathrm{p} 65$ and $\mathrm{I} \kappa \mathrm{B} \alpha$ were determined by western blot. GAPDH and Lamin B1 were used as references for total protein and nuclear protein, respectively. Representative images of three independent experiments are presented. (C) Relative DNA-binding activity. Data are shown as mean \pm SEM from three independent experiments performed in triplicate. ${ }^{* *} P<0.01 \mathrm{vs}$. the control group (untreated cells); $\# P<0.05$ vs. the LPS group.

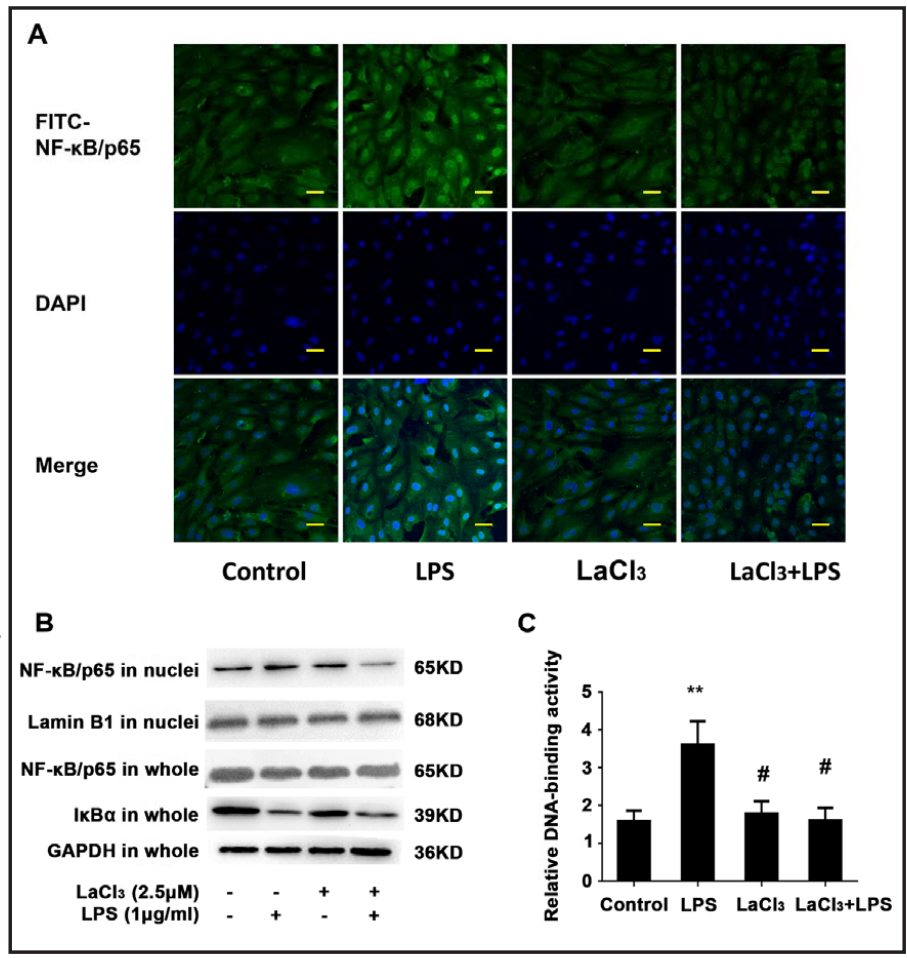

$\mathrm{LaCl}_{3}$ blocked LPS-induced $m R N A$ expressions and secretion of pro-inflammatory cytokines and adhesion molecules in HUVECS

As shown in Fig. 3A, LPS treatment induced significantly higher mRNA levels of TNF- $\alpha$, $I L-1 \beta, I L-6, I C A M-1$, and $M M P-9$ (all $P<0.05$ vs. control group). Pretreatment with $\mathrm{LaCl}_{3}$ reduced the LPS effects on TNF- $\alpha, I L-1 \beta, I L-6$, and MMP-9 expression, but promoted $C O X-2$ gene expression (all $P<0.05$ vs. the LPS group). Thus, COX-2 was not further studied. $\mathrm{LaCl}_{3}$ treatment alone had no effects on the mRNA levels of TNF- $\alpha, I L-1 \beta, I L-6, I C A M-1$, and MMP-9.

Then, we further observed the secretion of TNF- $\alpha$, IL-1 $\beta$, IL-6, ICAM-1, and MMP-9 in cell culture supernatant. Consistent with the RT-qPCR results, LPS stimulation caused a sharp increase in the production of TNF- $\alpha$, IL-1 $\beta$, IL-6, ICAM-1, and MMP-9 compared with the control group (all $P<0.001$ ). The results indicated that $\mathrm{LaCl}_{3}$ pretreatment inhibited LPSinduced increase in TNF- $\alpha$, IL-1 $\beta$, IL-6, ICAM-1, and MMP-9 levels, while $\mathrm{LaCl}_{3}$ treatment alone did not alter the secretion of TNF- $\alpha$, IL-1 $\beta$, IL-6, ICAM-1, and MMP-9 in cell culture supernatant (Fig. 3B).

$L P S$-induced recruitment of $N F-\kappa B / p 65$ to the gene promoter regions of pro-inflammatory cytokines and adhesion molecules was affected by the treatment of $\mathrm{LaCl}_{3}$ in $\mathrm{HUVECS}$

Using NF- $\kappa B / p 65$ ChIP-qPCR analysis, we found that the recruitment of NF- $\kappa B / p 65$ to the gene promoter region of MMP-9 and $I L-6$ (both $P<0.001$ ), TNF- $\alpha$ and ICAM-1 (both $P<$ $0.01)$, and $I L-1 \beta(P<0.05)$ was increased in the LPS group compared with the control group (Fig. 4). The NF- $\mathrm{KB} / \mathrm{p} 65$ recruitment to the above gene promoters was lower in the LPS + $\mathrm{LaCl}_{3}$ group compared with the LPS group (all $P<0.001$ ). Compared with the control group, the accumulation of NF- $\mathrm{KB} / \mathrm{p} 65$ of the $\mathrm{LaCl}_{3}$ group was up-regulated in the gene promoter region of TNF- $\alpha$ and ICAM-1 (both $P<0.05$ ). Meanwhile, the accumulation in MMP-9, IL-6, and $I L-1 \beta$ gene promoter regions was decreased compared with the LPS group (all $P<0.05$ ) (Fig. 4). These results suggest that $\mathrm{LaCl}_{3}$ can block LPS-induced NF- $\kappa \mathrm{B} / \mathrm{p} 65$ recruitment in pro-inflammatory cytokine and adhesion molecule genes' promoter, while $\mathrm{LaCl}_{3}$ alone had various effects on the recruitment of NF- $\mathrm{BB} / \mathrm{p} 65$ to each pro-inflammatory gene promoter. 
Fig. 3. $\mathrm{LaCl}_{3}$ blocked LPS-induced mRNA expression and secretion of pro-inflammatory cytokines and adhesion molecules in HUVECs. Endothelial cells were pretreated with $2.5 \mu \mathrm{M}$ of $\mathrm{LaCl}_{3}$ for $30 \mathrm{~min}$ followed by treatment in fresh medium with $1 \mu \mathrm{g} / \mathrm{ml}$ of LPS for $4 \mathrm{~h}$. (A) mRNA expressions of tumor necrosis factor (TNF)- $\alpha$, interleukin (IL)6, IL-1 $\beta$, cyclooxygenase (COX-2), matrix metalloproteinase (MMP)-9, and intercellular adhesion molecule (ICAM)-1 were determined by real-time RT-PCR. (B) Secretion of TNF- $\alpha$, IL-6, IL-1 $\beta$, MMP-9, and ICAM-1 in the cell culture supernatants was determined by ELISA. Data are shown as mean \pm SEM from three independent experiments preformed in triplicate. ${ }^{*} P$ $<0.05,{ }^{* *} P<0.01,{ }^{* * *} P<0.001 v s$. the control group; \#P<0.05, \#\#P $<0.01$, \#\#\#P<0.001 vs. the LPS group.

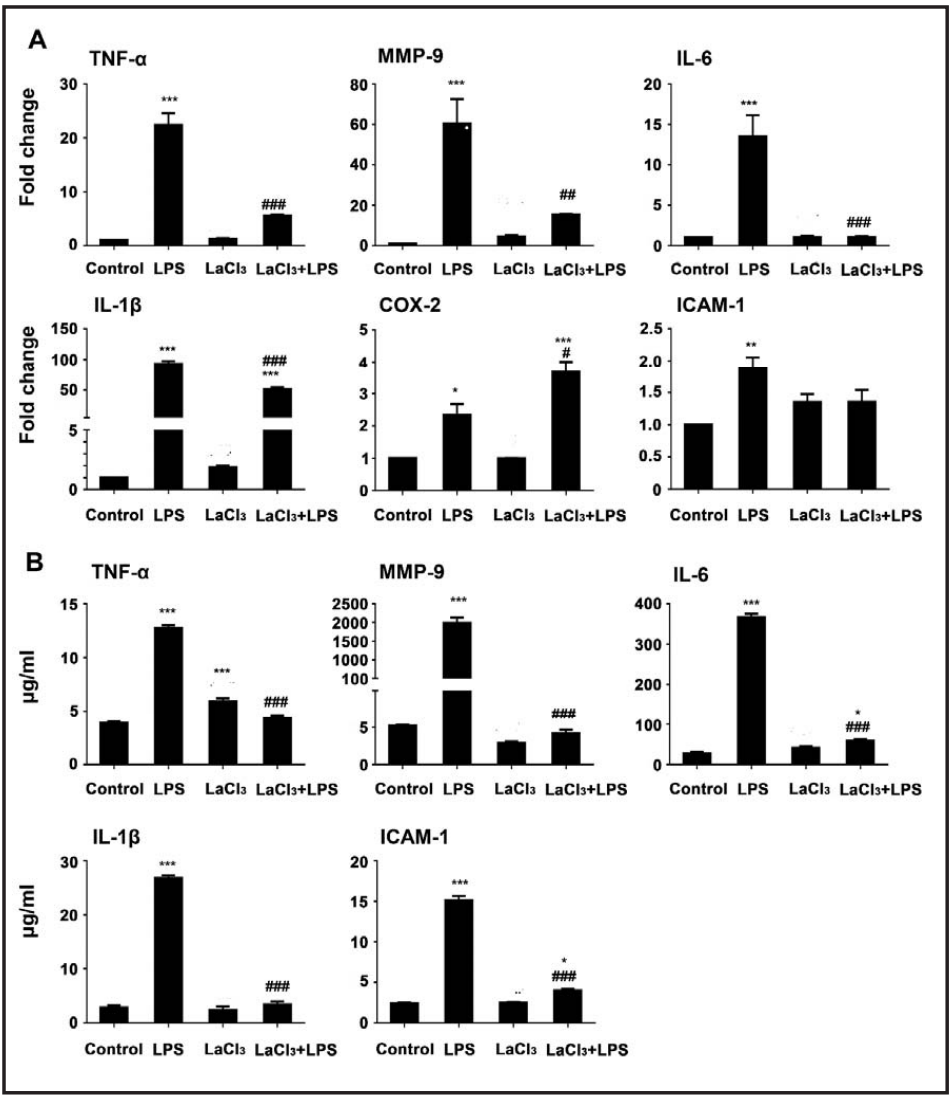

Effects of $\mathrm{LaCl}_{3}$ on LPS induction of Jmjd3 gene expression and recruitment of Jmjd3 to the gene promoter regions of the pro-inflammatory cytokines and adhesion molecules in HUVECS

Jmjd3 mRNA expression was induced by LPS treatment and the effect was significantly blocked by $\mathrm{LaCl}_{3}$ (both $P<0.001$ ). Jmjd3 expression in the $\mathrm{LaCl}_{3}$ group changed little compared with the control group $(P>0.05)$ (Fig. 5A). Jmjd3 protein expression was consistent with the results from real-time RT-PCR (Fig. 5B). Then we looked into the recruitment of Jmjd3 to the promoter regions of $T N F-\alpha, M M P-9, I L-6, I L-1 \beta$, and $I C A M-1$ (Fig. 5C). We found that in the LPS group, the enrichment of Jmjd3 to the TNF- $\alpha$ and MMP-9 (both $P<0.001$ ) gene promoters were increased compared with the control group. $\mathrm{LaCl}_{3}$ treatment blocked the LPS-induced enrichment of Jmjd3 to the promoter region of TNF- $\alpha, M M P-9$, and $I L-6$ (all $P<0.001$ ), and $I L-1 \beta(P<0.05)$. However, in the promoter region of ICAM-1, $\mathrm{LaCl}_{3}$ treatment increased the enrichment of Jmjd3 $(P<0.05)$. Surprisingly, we found that in the $\mathrm{LaCl}_{3}$ group the recruitment of Jmjd 3 to the TNF- $\alpha, I L-6$, and ICAM-1 promoter regions increased significantly.

Methylation status, as shown by $\mathrm{H} 3 \mathrm{~K} 2 \mathrm{Tme3}$, at the gene promoter regions of proinflammatory cytokines and adhesion molecules is altered by LPS and/or $\mathrm{LaCl}_{3}$ H3K27me3, the substrate of Jmjd3, is demethylated into H3K27me2/H3K27me to enable or enhance transcriptional activation [18]. By ChIP-qPCR, we found that $\mathrm{LaCl}_{3}$ lead to higher H3K27me3 levels at the promoter region of TNF- $\alpha(P<0.01)$ and ICAM-1 $(P<0.001)$, but lower H3K27me3 at the promoter region of $M M P-9$ compared with the control group $(P<$ $0.001)$. On the other hand, LPS treatment resulted in lower H3K27me3 levels at the promoter region of $M M P-9, I L-1 \beta$ and $I L-6$ compared with the control group (all $P<0.001$ ). When the cells were treated with LPS and $\mathrm{LaCl}_{3}$, the $\mathrm{H} 3 \mathrm{~K} 27$ me3 levels were a little higher than that of the LPS group but still lower than that of the control group. For $M M P-9, I L-6$, and $I L-1 \beta$ promoter regions, $\mathrm{H} 3 \mathrm{~K} 27 \mathrm{me} 3$ levels in the cells treated with $\mathrm{LPS}$ and $\mathrm{LaCl}_{3}$ were significantly lower than that of the control group $(P<0.01)$ (Fig. 6). 

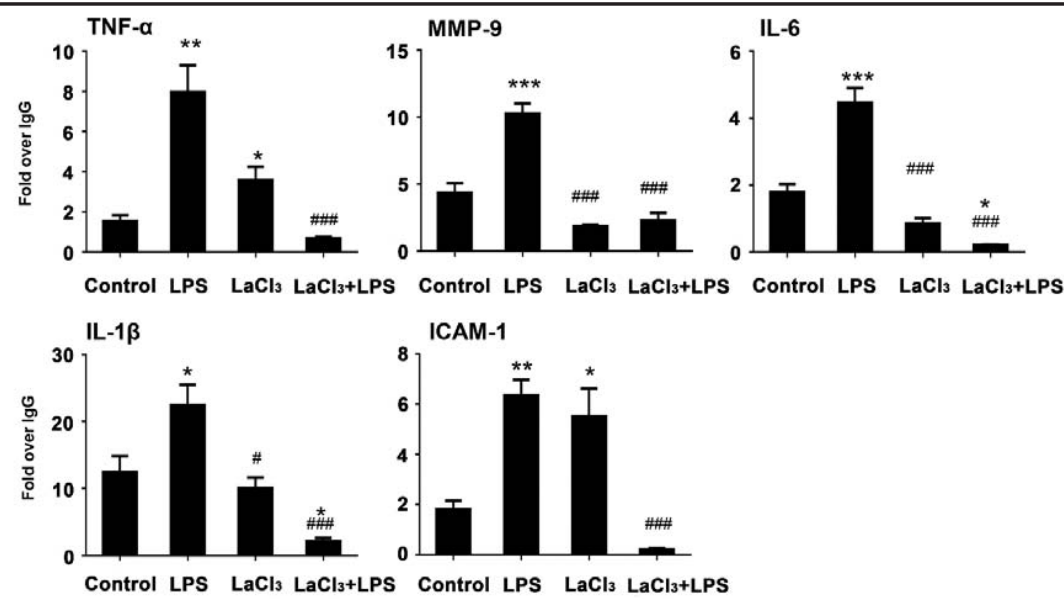

Fig. 4. $\mathrm{LaCl}_{3}$ attenuated LPS-induced recruitment of NF- $\mathrm{KB} / \mathrm{p} 65$ in the gene promoter regions of pro-inflammatory cytokines and adhesion molecules in HUVECs. Endothelial cells were pretreated with $2.5 \mu \mathrm{M}$ of $\mathrm{LaCl}_{3}$ for $30 \mathrm{~min}$ followed by treatment in fresh medium with $1 \mu \mathrm{g} / \mathrm{ml}$ of LPS for $2 \mathrm{~h}$. Recruitment of NF- $\kappa \mathrm{B} /$ p65 in the gene promoter regions of pro-inflammatory cytokines and adhesion molecules were determined by ChIP-qPCR. Data are shown as mean \pm SEM from three independent experiments preformed in triplicate. ${ }^{*} P<0.05,{ }^{* *} P<0.01,{ }^{* * *} P<0.001$ vs. the control group; $\# P<0.05$, \#\#\#P<0.001 vs. the LPS group.

Fig. 5. $\mathrm{LaCl}_{3}$ attenuated LPS-induced expression and recruitment of Jmjd3 in the gene promoter regions of pro-inflammatory cytokines and adhesion molecules in HUVECs. Endothelial cells were pretreated with $2.5 \mu \mathrm{M}$ of $\mathrm{LaCl}$ for $30 \mathrm{~min}$ followed by treatment in fresh medium with $1 \mu \mathrm{g} / \mathrm{ml}$ of LPS for 2 h. (A) Jmjd3 mRNA levels were detected by real-time RT-PCR. (B) Jmjd3 protein levels were detected by western blot. GAPDH was used as the inner control. (C) Jmjd3 in the gene promoter regions of pro-inflammatory cytokines and adhesion molecules was detected by ChIP-qPCR. Data are shown as mean \pm SEM

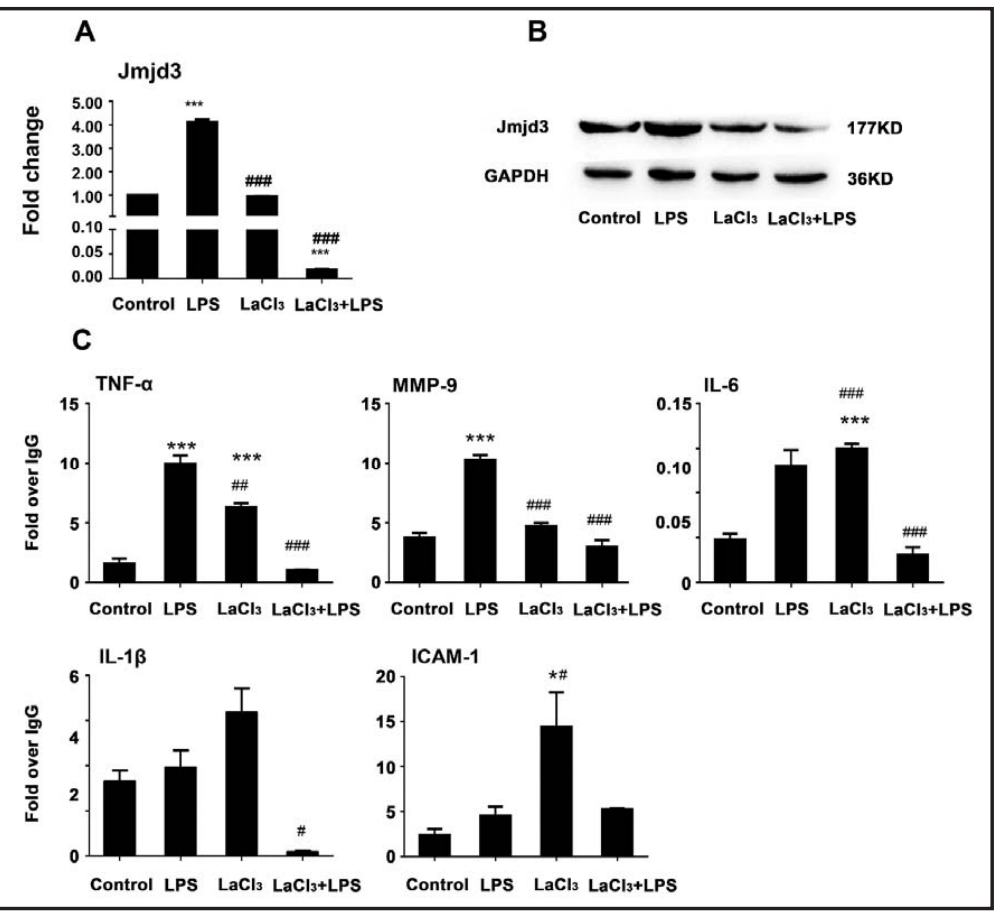
from three independent experiments preformed in triplicate. ${ }^{*} P<0.05$, ${ }^{* * *} P<0.001 v s$. the control group; $\# P<0.05$, \#\#P $<0.01$, \#\#\# $<0.001$ vs. the LPS group.

\section{Discussion}

NF- $\mathrm{kB} / \mathrm{p} 65$ activation and nuclear translocation are observed in endothelial cells, macrophages, and vascular smooth muscle cells during vascular inflammation [37]. Jmjd3 is triggered by NF- $\kappa B$ signaling, acts as a co-activator of NF- $\kappa B$, and epigenetically regulates inflammatory gene expression $[18,38]$. Jmjd3 specifically catalyzes H3K27me3 demethylation to H3K27me2 and H3K27me, and H3K27me is associated with activation of

\section{KARGER}


Fig. 6. Effect of $\mathrm{LaCl}_{3}$ on LPS-induced increase in the level of $\mathrm{H} 3 \mathrm{~K} 27 \mathrm{me} 3$ in the gene promoter regions of pro-inflammatory cytokines and adhesion molecules in HUVECs. Endothelial cells were pretreated with $2.5 \mu \mathrm{M}$ of $\mathrm{LaCl}$ for $30 \mathrm{~min}$ followed by treatment in fresh medium with $1 \mu \mathrm{g} / \mathrm{ml}$ of LPS for $2 \mathrm{~h} . \mathrm{H} 3 \mathrm{~K} 27 \mathrm{me} 3$ in the gene promoter regions of pro-inflammatory cytokines and adhesion molecules was de-

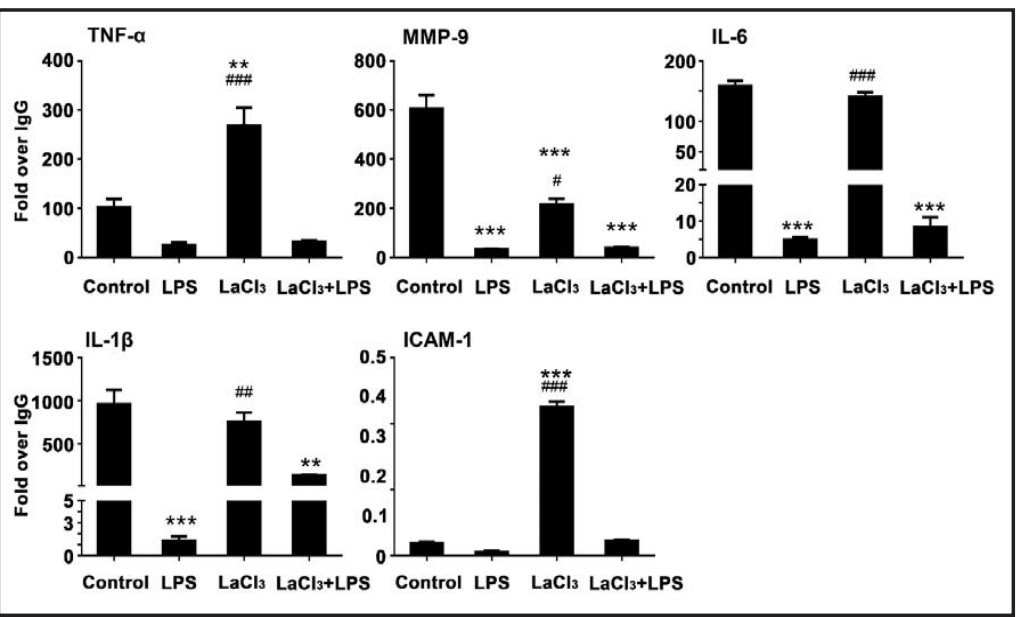
tected by ChIP-qPCR. Data are shown as mean \pm SEM from three independent experiments preformed in triplicate. ${ }^{* *} P<0.01,{ }^{* * *} P<0.001$ vs. the control group; $\# P<0.05, \# \# P<0.01$, \#\#\#P<0.001 vs. the LPS group.

gene transcription [39]. Based on our previous studies of the effects of lanthanum on NF$\kappa \mathrm{B}$ signaling in macrophages $[26,31]$ and the findings that exposure to metals affects the epigenome via histone modifying enzymes [40,41], we postulated that Jmjd3 and NF- $\kappa B$ could be potential targets being affected by lanthanum ions in endothelium cells.

In the present study, the results strongly suggest that $\mathrm{LaCl}_{3}$ significantly attenuates LPSmediated induction of TNF- $\alpha, I L-1 \beta, I L-6, I C A M-1$, and $M M P-9$, and that this $\mathrm{LaCl}_{3}$-induced attenuation is mediated through blocking p65 translocation to the nucleus, as supported by previous studies from our group [26,31]. Furthermore, Jmjd3 expression was induced by LPS treatment and the effect was significantly blocked by $\mathrm{LaCl}_{3}$. This $\mathrm{LaCl}_{3}$-induced attenuation was mediated through the blocking of the enrichment of NF- $\mathrm{KB} / \mathrm{p} 65$ and Jmjd3 at the gene promoter regions of TNF- $\alpha, M M P-9, I L-1 \beta$, and $I L-6$. These findings suggest new insights in the role of lanthanum ions on the regulation of the NF- $\mathrm{kB}-\mathrm{Jmjd} 3$ pathway.

The effects of Jmjd3 on inflammatory gene expressions are reported to be independent of its H3K27me3 demethylase activity [42]. Although the LPS-induced decrease of H3K27me3 level was found in target gene (TNF- $\alpha, M M P-9, I L-6$, and $I L-1 \beta$ ) promoter regions of HUVECs treated with both $\mathrm{LaCl}_{3}$ and LPS, the abovementioned gene expression remains blocked in the present study. When considering the effects of $\mathrm{LaCl}_{3}$ alone on these genes individually, H3K27me3 level in the promoter regions of TNF- $\alpha$ and ICAM-1 were higher than in controls, while H3K27me3 was downregulated in MMP-9 and did not show any change in $I L-1 \beta$ and $I L-6$. These results suggest that in addition to H3K27me3 demethylase activity, lanthanum might alter other Jmjd3 functions. Additional studies are necessary to examine the effects of $\mathrm{LaCl}_{3}$ on the regulation of inflammatory cytokines and adhesion molecules. Indeed, only a small panel of factors was examined.

Lanthanum has potential applications in medicine [22]. It is documented that treatment with $\mathrm{La}^{3+}$ enhances the capacity of the reactive oxygen species scavenging system [43], affects the $\mathrm{Fe}^{2+}$ and $\mathrm{Fe}^{3+}$ electron-transfer process in ferritin [44], and restrains the formation of hydroxyl radical, thereby alleviating the oxidative damage induced by PEG stress [44]. The activities of superoxide dismutase, catalase, ascorbate peroxidase, monodehydroascorbate reductase, dehydroascorbate reductase, glutathione reductase, and peroxidase were significantly increased after $\mathrm{La}^{3+}$ treatment $[44,45] . \mathrm{Fe}^{2+}$ and $\alpha$-ketoglutarate are required as cofactors of the demethylase family, which catalyzes the removal of methylation by a hydroxylation reaction and requires iron and $\alpha$-ketoglutarate as cofactors [46]. Therefore, it could be hypothesized that the lanthanum ion could change the structure of demethylases, enhance their binding to histones, and suppress their activity. However, histone methylation and demethylation regulation mechanisms are far beyond the demethylase activity of Jmjd3 
alone, and further comprehensive studies are needed to grasp the exact effects of lanthanum on epigenetics.

In conclusion, $\mathrm{LaCl}_{3}$ inhibited the activation of $\mathrm{NF}-\mathrm{\kappa B}$ and its downstream proinflammatory cytokines and adhesion molecules induced by LPS in HUVECs. These effects involved the histone demethylase Jmjd3 and demethylation of H3K27me3. These results suggest that lanthanum may have therapeutic benefits against atherosclerosis, diabetic complications, and other vascular inflammatory diseases, but additional studies are necessary.

\section{Acknowledgements}

This work was supported by the National Natural Science Foundation of China (81160193), Fellowship for young scientist of Jiangxi Province (20122BCB23027) and Science and Technology Planning Project of Health and Family Planning Commission of Jiangxi Province (20171061).

\section{Disclosure Statement}

All authors declare that they have no conflict of interests.

\section{References}


C: The inflammatory protein Pentraxin 3 in cardiovascular disease. Immun Ageing 2016;13:25.

$>2$ Taleb S: Inflammation in atherosclerosis. Arch Cardiovasc Dis DOI:10.1016/j.acvd.2016.04.002.

-3 Lozano I, Van der Werf R, Bietiger W, Seyfritz E, Peronet C, Pinget M, Jeandidier N, Maillard E, Marchioni E, Sigrist S, Dal S: High-fructose and high-fat diet-induced disorders in rats: impact on diabetes risk, hepatic and vascular complications. Nutr Metab (Lond) 2016;13:15.

-4 Berg AH, Scherer PE: Adipose tissue, inflammation, and cardiovascular disease. Circ Res 2005;96:939-949.

5 Malemud CJ: Matrix metalloproteinases (MMPs) in health and disease: an overview. Front Biosci 2006;11:1696-1701.

6 Lawson C, Wolf S: ICAM-1 signaling in endothelial cells. Pharmacol Rep 2009;61:22-32.

7 Grosser T, Fries S, FitzGerald GA: Biological basis for the cardiovascular consequences of COX-2 inhibition: therapeutic challenges and opportunities. J Clin Invest 2006;116:4-15.

-8 Song L, Kang C, Sun Y, Huang W, Liu W, Qian Z: Crocetin Inhibits Lipopolysaccharide-Induced Inflammatory Response in Human Umbilical Vein Endothelial Cells. Cell Physiol Biochem 2016;40:443-452.

-9 Rajendran P, Rengarajan T, Thangavel J, Nishigaki Y, Sakthisekaran D, Sethi G, Nishigaki I: The vascular endothelium and human diseases. Int J Biol Sci 2013;9:1057-1069.

10 Onat D, Brillon D, Colombo PC, Schmidt AM: Human vascular endothelial cells: a model system for studying vascular inflammation in diabetes and atherosclerosis. Curr Diab Rep 2011;11:193-202.

-11 Zhou Z, You Z: Mesenchymal Stem Cells Alleviate LPS-Induced Acute Lung Injury in Mice by MiR-142a-5pControlled Pulmonary Endothelial Cell Autophagy. Cell Physiol Biochem 2016;38:258-266.

12 Yin X, Liang Z, Yun Y, Pei L: Intravenous Transplantation of BMP2-Transduced Endothelial Progenitor Cells Attenuates Lipopolysaccharide-Induced Acute Lung Injury in Rats. Cell Physiol Biochem 2015;35:21492158.

13 Jenuwein T, Allis CD: Translating the histone code. Science 2001;293:1074-1080.

14 Shu XZ, Zhang LN, Zhang R, Zhang CJ, He HP, Zhou H, Wang N, Zhang TC: Histone acetyltransferase p300 promotes MRTF-A-mediates transactivation of VE-cadherin gene in human umbilical vein endothelial cells. Gene 2015;563:17-23. 


\section{Cellular Physiology Cell Physiol Biochem 2017;42:1713-1724 \begin{tabular}{l|l} 
DOI: 10.1159/000479439 2017 & $\begin{array}{l}\text { O 2017 The Author(s). Published by S. Karger AG, Basel } \\
\text { www.karger.com/cpb }\end{array}$
\end{tabular}}

Chen et al.: $\mathrm{LaCl}_{3}$ Inhibited Inflammation in LPS-Induced HUVECS

15 Yu X, Ling W, Mi M: Relationship of impairment induced by intracellular S-adenosylhomocysteine accumulation with DNA methylation in human umbilical vein endothelial cells treated with 3-deazaadenosine. Int J Exp Pathol 2009;90:638-648.

16 Morey L, Helin K: Polycomb group protein-mediated repression of transcription. Trends Biochem Sci 2010;35:323-332.

17 Lan F, Bayliss PE, Rinn JL, Whetstine JR, Wang JK, Chen S, Iwase S, Alpatov R, Issaeva I, Canaani E, Roberts TM, Chang HY, Shi Y: A histone H3 lysine 27 demethylase regulates animal posterior development. Nature 2007;449:689-694.

18 De Santa F, Narang V, Yap ZH, Tusi BK, Burgold T, Austenaa L, Bucci G, Caganova M, Notarbartolo S, Casola S, Testa G, Sung WK, Wei CL, Natoli G: Jmjd3 contributes to the control of gene expression in LPS-activated macrophages. EMBO J 2009;28:3341-3352.

19 Yuan ZK, Liu Y, Yu HQ, Zheng HL, Wang NF, Wu MK, Liu YT, Hao SM: Study on relaitionship between rare earth level in blood and health condiction of residnents. China public health 2003;19:133-135.

20 Eski M, Ozer F, Firat C, Alhan D, Arslan N, Senturk T, Isik S: Cerium nitrate treatment prevents progressive tissue necrosis in the zone of stasis following burn. Burns 2012;38:283-289.

21 Oen IM, van Baar ME, Middelkoop E, Nieuwenhuis MK, Facial Burns G: Effectiveness of cerium nitrate-silver sulfadiazine in the treatment of facial burns: a multicenter, randomized, controlled trial. Plast Reconstr Surg 2012;130:274e-283e.

-22 Zherdeva VV, Savitsky AP: Using lanthanide-based resonance energy transfer for in vitro and in vivo studies of biological processes. Biochemistry (Mosc) 2012;77:1553-1574.

-23 Prajapati VA, Galani VJ, Shah PR: A comparative study of phosphate binders in patients with end stage kidney disease undergoing hemodialysis. Saudi J Kidney Dis Transpl 2014;25:530-538.

24 Gotoh J, Kukita K, Tsuchihashi S, Hattori M, Iida J, Horie T, Onodera K, Furui H, Tamaki T, Meguro J, Yonekawa M, Kawamura A: Study of prolonged administration of lanthanum carbonate in dialysis patients. Ther Apher Dial 2013;17:9-14.

25 Manabe R, Fukami K, Ando R, Sakai K, Kusumoto T, Hazama T, Adachi T, Kaida Y, Nakayama Y, Ueda S, Kohno K, Wada Y, Yamagishi S, Okuda S: Effects of switching from calcium carbonate to lanthanum carbonate on bone mineral metabolism in hemodialysis patients. Ther Apher Dial 2013;17:35-40.

26 Guo F, Guo X, Xie A, Lou YL, Wang Y: The suppressive effects of lanthanum on the production of inflammatory mediators in mice challenged by LPS. Biol Trace Elem Res 2011;142:693-703.

27 Li B, Xie Y, Cheng Z, Cheng J, Hu R, Cui Y, Gong X, Shen W, Hong F: Effects of added CeCl3 on resistance of fifth-instar larvae of silkworm to Bombyx mori nucleopolyhedrovirus infection. Biol Trace Elem Res 2012;146:318-324.

28 Shi P, Z. H: Proteomic detection of changes in protein synthesis induced by lanthanum in BGC-823 human gastric cancer cells. Biometals 2005;18:89-95.

29 Yu L, Xiong J, Guo L, Miao L, Liu S, Guo F: The effects of lanthanum chloride on proliferation and apoptosis of cervical cancer cells: involvement of let-7a and miR-34a microRNAs. Biometals 2015;28:879-890.

-30 Heffeter P, Jakupec MA, Korner W, Wild S, von Keyserlingk NG, Elbling L, Zorbas H, Korynevska A, Knasmuller S, Sutterluty H, Micksche M, Keppler BK, Berger W: Anticancer activity of the lanthanum compound [tris(1,10-phenanthroline)lanthanum(III)]trithiocyanate (KP772; FFC24). Biochem Pharmacol 2006;71:426-440.

-31 Guo F, Lou Y, Feng N, Li G, Xie A, Huang X, Wang Y: Exposure to lanthanum compound diminishes LPSinduced inflammation-associated gene expression: involvements of PKC and NF-kappaB signaling pathways. Biometals 2010;23:669-680.

32 Bu DX, Erl W, de Martin R, Hansson GK, Yan ZQ: IKKbeta-dependent NF-kappaB pathway controls vascular inflammation and intimal hyperplasia. FASEB J 2005;19:1293-1295.

33 Marin V, Kaplanski G, Gres S, Farnarier C, Bongrand P: Endothelial cell culture: protocol to obtain and cultivate human umbilical endothelial cells. J Immunol Methods 2001;254:183-190.

-34 Geranmayeh MH, Baghbanzadeh A, Barin A, Salar-Amoli J, Dehghan MM, Rahbarghazi R, Azari H: Paracrine Neuroprotective Effects of Neural Stem Cells on Glutamate-Induced Cortical Neuronal Cell Excitotoxicity. Adv Pharm Bull 2015;5:515-521. 


\section{Cellular Physiology Cell Physiol Biochem 2017;42:1713-1724 \begin{tabular}{l|l} 
and Biochemistry Published online: July 25, 2017 & $\begin{array}{l}\text { () } 2017 \text { The Author(s). Published by S. Karger AG, Basel } \\
\text { www.karger.com/cpb }\end{array}$ \\
\hline
\end{tabular}}

-35 Sultana F, Rasool M: A novel therapeutic approach targeting rheumatoid arthritis by combined administration of morin, a dietary flavanol and non-steroidal anti-inflammatory drug indomethacin with reference to pro-inflammatory cytokines, inflammatory enzymes, RANKL and transcription factors. Chem Biol Interact 2015;230:58-70.

-36 Valovka T, Hottiger MO: p65 controls NF-kappaB activity by regulating cellular localization of IkappaBbeta. Biochem J 2011;434:253-263.

-37 Brand K, Page S, Rogler G, Bartsch A, Brandl R, Knuechel R, Page M, Kaltschmidt C, Baeuerle PA, Neumeier D: Activated transcription factor nuclear factor-kappa B is present in the atherosclerotic lesion. J Clin Invest 1996;97:1715-1722.

38 Li Y, Reddy MA, Miao F, Shanmugam N, Yee JK, Hawkins D, Ren B, Natarajan R: Role of the histone H3 lysine 4 methyltransferase, SET7/9, in the regulation of NF-kappaB-dependent inflammatory genes. Relevance to diabetes and inflammation. J Biol Chem 2008;283:26771-26781.

-39 Rothbart SB, Strahl BD: Interpreting the language of histone and DNA modifications. Biochim Biophys Acta 2014;1839:627-643.

40 Guo X, Zhang Y, Zhang Q Fa P, Gui Y, Gao G, Cai Z: The regulatory role of nickel on H3K27 demethylase JMJD3 in kidney cancer cells. Toxicol Ind Health 2016;32:1286-1292.

41 Chervona Y, Arita A, Costa M: Carcinogenic metals and the epigenome: understanding the effect of nickel, arsenic, and chromium. Metallomics 2012;4:619-627.

-42 Przanowski P, Dabrowski M, Ellert-Miklaszewska A, Kloss M, Mieczkowski J, Kaza B, Ronowicz A, Hu F, Piotrowski A, Kettenmann H, Komorowski J, Kaminska B: The signal transducers Stat1 and Stat3 and their novel target Jmjd3 drive the expression of inflammatory genes in microglia. J Mol Med (Berl) 2014;92:239254.

43 Zhang L, Zeng F, Xiao R: Effect of lanthanum ions (La3+) on the reactive oxygen species scavenging enzymes in wheat leaves. Biol Trace Elem Res 2003;91:243-252.

44 Zhang L, Yang T, Gao Y, Liu Y, Zhang T, Xu S, Zeng F, An L: Effect of lanthanum ions (La3+) on ferritinregulated antioxidant process under PEG stress. Biol Trace Elem Res 2006;113:193-208.

45 Guo B, Xu LL, Guan ZJ, Wei YH: Effect of lanthanum on rooting of in vitro regenerated shoots of Saussurea involucrata Kar. et Kir. Biol Trace Elem Res 2012;147:334-340.

46 Whetstine JR, Nottke A, Lan F, Huarte M, Smolikov S, Chen Z, Spooner E, Li E, Zhang G, Colaiacovo M, Shi Y: Reversal of histone lysine trimethylation by the JMJD2 family of histone demethylases. Cell 2006;125:467481. 